\title{
Mineral Resource Depletion: A Coming Age of Stockpiling?
}

\author{
Ugo Bardi ${ }^{1} \cdot$ Rolf Jakobi $^{2} \cdot$ Hiroshan Hettiarachchi ${ }^{3}$
}

Received: 8 December 2015/Accepted: 11 May 2016/Published online: 27 May 2016

(C) Springer International Publishing Switzerland 2016

\begin{abstract}
The gradual depletion of low cost (or "high grade") mineral ores is generating increasing extractive costs and diminishing economic returns. The market reacts to this situation either with high prices, which depress demand, or with very low prices (as it is happening at present) that reduce or eliminate profits for the extractive industry, which is forced to reduce production. As a consequence, it is becoming increasingly difficult to manage the remaining mineral resources in such a way to ensure a sufficient supply for the economy and to avoid price shocks originated by the vagaries of the market or by social or strategic conflicts. This is particularly important for critical and rare metals, such as those needed by the electronic industry and for vital tasks such as the conversion and the transmission of electrical energy produced by renewable (e.g. photovoltaic) plants. One possible reaction to these problems is stockpiling, that is keeping mineral resources stored above ground and readily available in order to provide a buffer against price and supply shocks. The present paper discusses several ways in which the market of mineral resources could evolve, in particular the concept
\end{abstract}

Rolf Jakobi

ugo.bardi@unifi.it

1 Dipartimento di Scienze della terra, Università di Firenze, and Consorzio Interuniversitario per la Scienza e la tecnologia dei materiali (INSTM), Unità di Ricerca di Firenze, Polo Scientifico di Sesto Fiorentino, 50014 Sesto Fiorentino, Firenze, Italy

2 University of Applied Science Ludwigshafen, Ernst-BoeheStrasse 4, 67059 Ludwigshafen/Rhein, Germany

3 United Nations University - Institute for Integrated Management of Material Fluxes and of Resources (UNUFLORES), Ammonstrasse 74, 01067 Dresden, Germany of a "metal bank" that could be used to manage the supply of rare and sensitive minerals.

Keywords Mineral depletion - Mineral commodities . Rare minerals · Mineral stockpiling · Metal bank

\section{Introduction: The Depletion Problem}

Mining is an economically feasible activity because the energy costs associated with extracting materials dispersed in the earth's crust have been paid, in large part, by past geological and biological processes (Bardi 2014). These processes created high concentration (also termed "high grade") mineral deposits which are the ones exploited in commercial mining. However, as high-grade resources are processed and dispersed in the ecosystem, they have to be replaced with lower grade ones. As a result, no matter what the vagaries of market prices, the cost of mining is increasing as the result of the increasing need of energy and materials for the extraction process. This is the essence of the concept of "depletion", which does not mean "running out" of something, but involves diminishing economic returns.

The diminishing economic returns of mining had been identified already in 19th century by Jevons (1866). Much later, quantitative models for the effect of the increasing energy costs of mining were developed, such as the classic "The Limits To Growth" study of 1972 (Meadows 1972). These early results have been confirmed and refined in later studies (Meadows et al. 2004; Turner 2008; Sverdrup et al. 2012) and also described in quantitative terms based on thermodynamics (Valero and Valero 2014). Today, the effect of the diminishing returns of mining on the world economy is the object of a lively debate. Human ingenuity 
and market factors are often seen as being able to counteract physical depletion, and hence able to maintain an increasing supply of mineral commodities to the world's economy. A fundamental component of this interpretation is that technological progress can reduce mining costs, even though it can be argued that it cannot reverse the depletion process (Bardi 2014). The view that depletion will not affect the capability of the world's economy to keep growing was expressed perhaps for the first time in (Barnett and Morse 1963) and expressed again by several authors (see, e.g. Houthakker 2002; Bradley 2007).

Without entering into the details of the debate, a number of observations indicate that depletion is starting to become an important problem for the world's economy. While it is true that most mineral commodities show no evidence of a decrease in production, it is also true that the growth trends have been slowing (Brown et al. 2013). We can also observe that, during the past decade or so, the mineral commodity market has been showing a robust trend of price increases, even though associated with strong oscillations and by the reverse trend in recent times (Jacks 2013). In addition, the growth of the world's economy is slowing down, even for the case of the emerging Chinese economy (Popescu and Nica 2014). The same kind of slowdown is taking place for world trade (Constantinescu et al. 2015). These observations seem to be consistent with the "base case" scenario reported in "The Limits to Growth" (Meadows et al. 2004) which projects a decline of the world's economy as the result of increasing costs of mineral production which is reflected on the financial system with the pauperization of a large fraction of the consumers, which depresses demand. Although the debate on depletion remains open and ongoing, we cannot neglect the fundamental fact that the extractive industry tends naturally to start with the "low hanging fruit" and to move gradually to more expensive resources. The market must adapt in some way to increasing extractive costs. Depletion may also exacerbate the problem that many critical elements, which are essential for high-tech applications, come from regions which are politically and economically unstable and show high rates of corruption (Jakobi 2014).

In the long term, the only possible strategy to eliminate the depletion problem is to move to a "circular" economy, where all the resources used in industrial production are completely recycled - this is not impossible, provided that sufficient energy is available (Bianciardi et al. 1993) and there is evidence that the world's industrial system is moving in that direction (Ashby 2016). However, restructuring the whole industrial system in terms of a circular management of all mineral resources is a complex and expensive task, also incompatible with the concept of "economic growth" as it is understood today. In the short and medium term, market factors are rather likely to force the industrial system to use less resources. At the same time, "supply shocks" have been already observed in the past for some specific commodities, such as for crude oil in the "oil shock" of the 1970s and for rare earths in recent years (Areddy 2011). It is possible that new shocks will be observed in the future as depletion becomes a more and more important problem, especially for rare and expensive minerals used in the electronics industry (Jakobi 2011). One possible reaction of the economy and of the industrial system to these problems may consist in stockpiling resources, keeping them readily available in order to ensure supply in any moment. This is the subject of the present paper, where we examine in particular the concept of stockpiling resources to use as a buffer against supply shocks. In particular, we examine the concept of a "metal bank" that could be used in particular for rare and expensive mineral commodities relevant to the electronics industry.

\section{Market Trends and Stockpiling}

The idea of stockpiling resources may find a justification in the best known model of management of mineral resources in economics that is the Hotelling rule (Hotelling 1931), which posits that extracting companies will gradually reduce production while, at the same time, raising prices. This strategy maximizes the economic yield of the resource over its complete extraction cycle; that is, until a new, "backstop" resource is assumed to take over. This principle can be also referred to as the "principle of infinite substitutability" that sees how all rare minerals can be replaced by abundant ones as a result of technological progress and the availability of abundant resources (Goeller and Weinberg 1978). Up to not long ago, the results of Hotelling's rule were rarely observed in the real world of the mining industry. Rather than growing prices and declining extraction rates, the market saw the exact contrary over the past century or so; that is, constant or diminishing prices and increasing extraction rates. This result led some to conclude that mineral resources were extremely abundant, even "infinite" (e.g. Simon 1981, 1996). More likely, however, resources were abundant enough for the short-term view of most operators that their depletion was not an important factor in planning their exploitation (Reynolds 1999). But the trend has changed during the past decade or so. Nowadays, we are seeing what appears like a trend of increasing commodity prices which is accompanied by a slowdown of the trend of growing production normally observed up to now. As an example, Fig. 1 shows the prices (corrected for inflation) of crude oil (Brent) over ca. a century. 
Fig. 1 Brent crude oil prices. Data up to 2014 from www.bp. com, datum for 2015 from www.statista.com, scaled to 2013 dollars using data from the bureau of labour statistics, http://www.bls.gov/data/ (both statista.com and bls.gov accessed on March 7 2016)

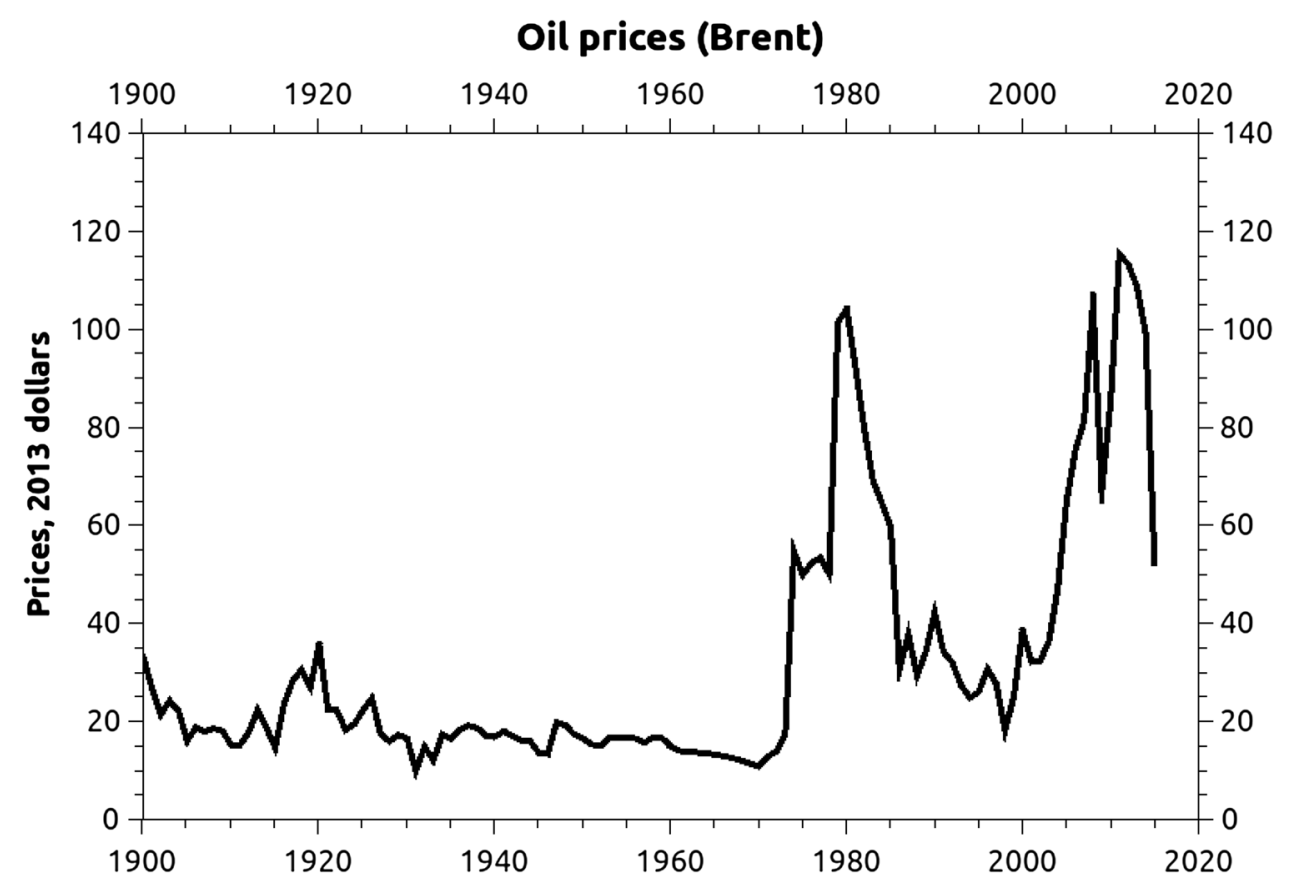

Despite the strong short-term price oscillations, the trends in the prices of crude oil have seen a considerable change after ca. 1970 in comparison to the previous period. Strong oscillations may mask the average trend, but if we take a long-term average, the values after ca. 1970 are much larger than before and increasing. This is the expected result of the increasing costs of extraction generated by depletion. While it is true that the latest data show a collapse in oil prices, it is also evident that, when this collapse is seen in its historical context, it can only be understood as a temporary oscillation, similar to others observed in the past.

The trend appears to be the same for most mineral commodities which have been showing a rising price trend since the 1960s (Jacks 2013). As an example, we report here the prices of grade A copper cathode (Fig. 2).

As a final example, we show the overall trend of metal commodity futures (Fig. 3).

From these data, we can conclude that all mineral commodities show strong oscillations superimposed to an average trend of increase. These trends are consistent with increasing production prices and with the attempt of the market to adapt to them. Therefore, the management of exhaustible natural resources may require moving away from a perception of abundance to a perception of scarcity and to expect supply shocks and wild price oscillations.

A possible strategy against these tendencies is to stockpile resources in the expectation of supply shocks with the idea of selling the resources accumulated in times of low prices in order to maintain supply. Of course, the actual profitability of such a strategy depends on several factors, physical and economic ones, and there exist at least three possible strategies for stockpiling resources: (i) keeping resources underground, (ii) stockpiling resources as waste in landfills and (iii) stockpiling resources above ground in specifically created facilities.

\section{Keeping Resources Underground}

Keeping mineral resources underground means that they are not extracted, even though they could be. This idea goes against the grain of the current way of thinking in economics, which emphasizes short-term profits. For instance, when the North Sea oil resources were discovered, in the 1970s, they were aggressively extracted and marketed at the fastest possible speed, mainly during the 1980s. This happened in a period of low market prices and it can be argued that, by keeping these resources underground, they could have been exploited at a later time with much larger profits for producers. In more recent times, the concept of "oil protocol" was proposed by Colin Campbell in 1996 (Heinberg 2006); that is of an international agreement to limit petroleum extraction in order to keep part of the existing resources underground and slow down the effects of depletion. This idea, however, was never put into practice.

Nevertheless, some producers do appear to manage their resources in ways that are conceived in order to lengthen their duration. This is typical of governments, which may act on the basis of long-term strategic considerations. An especially interesting case is that of rare earths. Considering that China, alone, produces more than $90 \%$ of the 
Fig. 2 Grade A copper cathode prices in dollars per metric ton (not corrected for inflation). Data from www.indexmundi. com, accessed March 13, 2016

Fig. 3 Metal commodities index according to www. indexmundi.org that includes Copper, Aluminium, Iron Ore, Tin, Nickel, Zinc, Lead and Uranium, data from www. indexmundi.org (accessed March 13, 2016)
Copper, grade A cathode Monthly Price

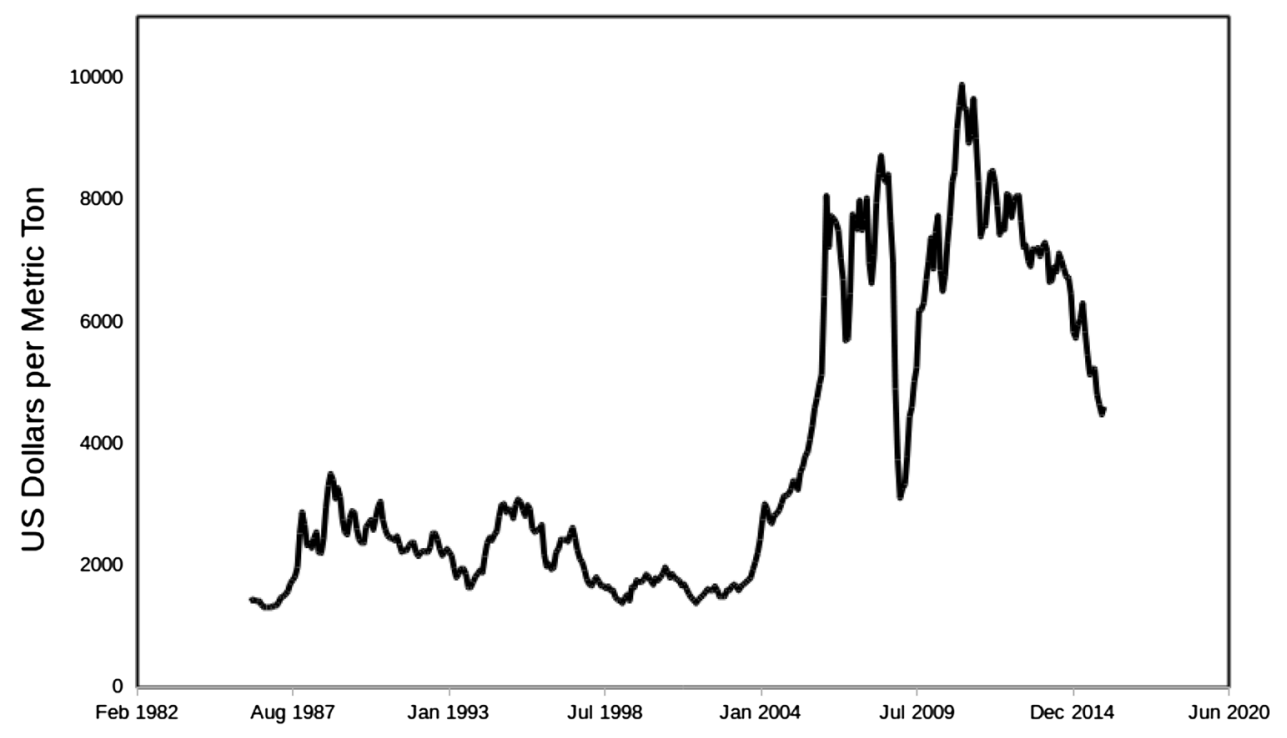

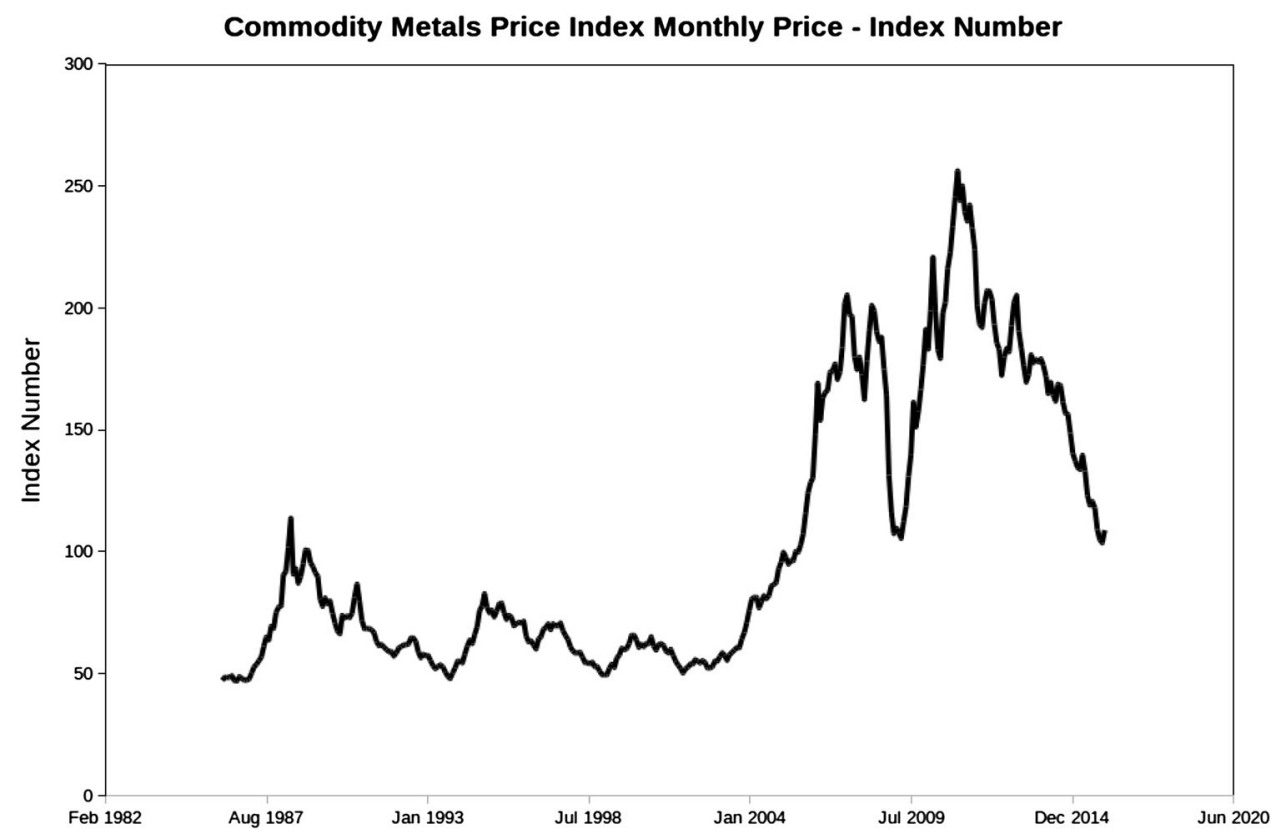

world's rare earth supply, (Stephenson 2013) the Chinese government is possibly the closest known entity which can totally dominate the marketing rate of a single mineral resource. Indeed, China was accused to have implemented a "rare earth embargo" in 2010 in order to raise the prices of the resource (Areddy 2011). However, this accusation turned out to be groundless as the prices of rare earths came back to reasonable values after a speculative spike that lasted about 1 year.

In a different extractive area, Saudi Arabia is often described as managing its oil resources by keeping them unextracted in ways that counteract price swings. That is,
Saudi Arabia is reported to increase oil production in times of high market prices and to lower it in times of low prices (Simmons 2005). However, the role of Saudi Arabia as the world's main "swing producer" is far from being demonstrated, since oil prices have been widely swinging up and down during the past decades. Furthermore, in the recent collapse of the oil prices, that started in 2014 and is ongoing, the Saudi made no major attempt to control prices by decreasing the amount of exported oil. At best, therefore, it is possible to argue that in some occasions the Saudi policy has acted in such a way to limit price swings. It has also been claimed that Saudi Arabia has refrained from 
prospecting for oil in some areas of its territory in order to keep it for future exploitation. This is, again, not proven (Ace 2008).

Apart from the cases just described, there is no clear evidence that any government or industrial company has ever consistently used the strategy of keeping a resource underground, while it could be instead be produced and sold at a profit on the world's market. One of the problems is that, in a free market economy, governments have no power to force private companies to stop producing a mineral resource. Another obvious problem is that the decision by a country to limit or to stop extraction of a resource on its territory is tantamount to an embargo directed against those countries which do not have similar resources available. At the extreme limit, such an action may invite military retaliation, as it has happened, for instance, at the time of the Arab oil embargo of the first oil crisis of the 1970s. Because of these considerations, simply leaving resources underground does not appear as a strategy that could be widely implemented in the future.

\section{Landfills as Stockpiled Resources}

In chemistry, nothing is ever created or destroyed, so the minerals laboriously extracted from mines do not disappear. They just end their trajectory underground again, after having gone through the industrial and marketing cycle. At the other end of the mining process, the extracted and processed minerals are dispersed in the environment in various forms and, in part, are dumped into landfills as waste, often after having gone through an incineration treatment. The question is whether landfills can be considered as a future strategic supply of minerals, usable to mitigate the depletion problem.

The concept of landfills as the "new mines" or "secondary mines" has been proposed many times (see, e.g. Krook et al. 2013). The problem is, however, that landfills have never been designed to be mines. In the simplest version of landfilling, waste is thrown more or less at random into a pile. More modern landfill technologies use some structuring of the deposited layers, but there is usually no attempt to separate or concentrate the most valuable metals dumped. Separate collection of urban waste does not usually imply the separation of different metals, except for some special cases, such as the aluminium of beverage cans. Magnetic metals, such as iron, can be easily separated from undifferentiated waste, but, in general, extracting metals from urban or industrial landfills requires intensive manual labour by operators who are also exposed to dangers such as bacterial contamination or pollution from other substances present in the waste. When, instead, waste goes through incineration before ending up in a landfill, then all the metals it contained are fused together in a glassy "cake" out of which recovering specific metals would be extremely expensive.

So far, therefore, the concept of landfills as secondary mines has remained mainly theoretical, although it has found application in some specific social contexts where "participatory collective waste management" (Gutberlet 2010; Tremblay et al. 2010) has been found to produce positive social effects in the poorest range of population. In quantitative terms, however, this approach has led so far to only minuscule amounts of metals being recovered and recycled. Hence, stockpiling significant amounts metals in landfills with the objective of recovering them in a future situation of scarcity, has not been a viable strategy, so far. It may be possible to improve in the future by enacting laws which would force the separate collection of different elements and perhaps their disposal in ways which make recovery easier. In this sense, the laws that regulate the disposal of "electronic waste" (Buchert et al. 2012) in OECD countries are a first step. However, the road is still long before this strategy can become a major factor in mitigating the future scarcity of mineral resources.

\section{Industrial Stockpiling}

Laboriously extracting a mineral resource from somewhere to store it somewhere else may appear as a self-defeating strategy, but stockpiling after extraction has advantages. One is that the stockpiled resource is already processed and refined and that it can be, therefore, marketed fast and at minimal costs. Then, it is a strategy that can be applied anywhere, independently of whether a country or a region have or not a certain mineral resource. Even producing countries can stockpile their mineral resources with the strategic objective of depleting the resources of other producing countries, while keeping their own untouched. This is the case, for instance, of the oil strategic reserve kept by the USA, one of the world's largest oil producers (CIA 2014). This reserve is able, alone, to keep the US economy running for more than a month at the current consumption levels. Several other countries also keep strategic oil reserves, although none is as large as the US one.

Another case of stockpiled strategic reserves is that of helium in the USA (CIA 2014) which was originally established in view of the need of helium as gas for airships. Then, China has been reported to plan to build a strategic storage site for rare-earth metals (Areddy 2011), although the present status of the project is unclear. Stockpiling mineral resources as a strategy has been extensively discussed in a report from the US Department of Defense (Strategic and Critical Materials 2013 Report on Stockpile Requirements 2013), but, as far as it is known, no other mineral resource besides oil and helium has been 
extensively stored in the USA. Outside the USA, Japan has been especially active in stockpiling strategic resources, and it has been reported that supplies of rare metals are kept for an equivalent to 42 days of standard consumption (Jogmec n.d.). An international "thorium energy bank" was also proposed (Kamei 2012).

The problem with above ground stockpiling is mainly a problem of cost. This cost, in turn, depends on the physical characteristics the resource to be stored. Resources which occupy large volumes, in particular those which exist in gaseous or liquid forms (e.g. oil and gas), are expensive to stock and are stored mainly in geological reservoirs (salt domes), rather than in artificial ones. In practice, all economies stockpile mineral resources in one form or another within their industrial systems, but their management, so far, has never been considered an issue. A more generalized approach will be discussed more in detail in the next section.

\section{The "Metal Bank"}

In this section, we discuss a possible strategic stockpiling method that might overcome the shortcoming of the methods described in the previous sections. A "Metal Bank" would not just stockpile rare metals, but would actively trade them and manage them in such a way to obtain economic profits while reducing or eliminating the risk of supply shocks generated by political or economic factors.

The concept of metal bank derives from the observation that, historically, banks have stockpiled and stored minerals; mainly precious metals such as gold. Could this strategy be expanded to the storage of other mineral commodities? Of course, we can hardly see a bank storing in its vaults the large amounts produced for some mineral resources, such as steel or crude oil (to say nothing of the safety problems involved). But it would be reasonably possible for a bank to store rare resources which are produced in volumes comparable to those of gold, are stable in a solid form and occupy small volumes without being poisonous or unsafe for other reasons. A good example could be platinum whose production is less than $200 \mathrm{t} / \mathrm{year}$ worldwide, nearly an order of magnitude smaller than that of gold. Storing a few years of platinum production in vaults would be easy to do, considering that, today, the gold reserves (gold stored in bank vaults) of the USA alone amount to more than $8000 \mathrm{t}$ (Sprott and Baker 2012). The same would be true for rare metals used in the electronics industry, such as indium, gallium, rare earths and others.

Of course, however, the problems of storing metals which have important industrial applications are different than those of gold, whose main application is as monetary value storage. In the following, we will sketch some elements of how a metal bank for rare metals could work.

The scheme of a practical "metal bank" is shown in Fig. 4. It can be seen as a private inter-company business with a self-assisting function among the participating companies. It builds up a physical stock of critical metals by long-term contracts with mines and smelters, as well as with recyclers in order to increase its physical metal stock. Once the bank has a sufficiently large stock, it issues certificates which are backed by $100 \%$ with physical material and can be traded between producers and users who foresee the need of the material for future use. With these certificates, producers can buy material from the metal bank or trade them among other participants if their needs have changed with time.

The metal bank would not be necessarily be operated by a government, but might well be an independent entity operating along the known mechanism of "future contracts". In the case of supply interruptions, the bank could release parts of its physical reserves to reduce the impact of the shock. Of course, such a bank would likely face shortterm economic losses, owing to missed marketing opportunities in case of a sustained period of oversupply. However, these losses could be recovered by the release of the stockpiled resources in moments of scarcity and-consequentially - high prices. The concept is well known: After all, any bank holding gold reserves is stockpiling gold as a strategic resource. Customers tend to sell or buy gold as a function of the way they perceive the market, just as it is normal for all mineral commodities, except that (normally) only gold is backed by stored physical reserves.

Of course, there is the question of whether private investors and producers would find it convenient to invest in the metal bank. This is a question that can only be

\section{Model of Metal Bank}

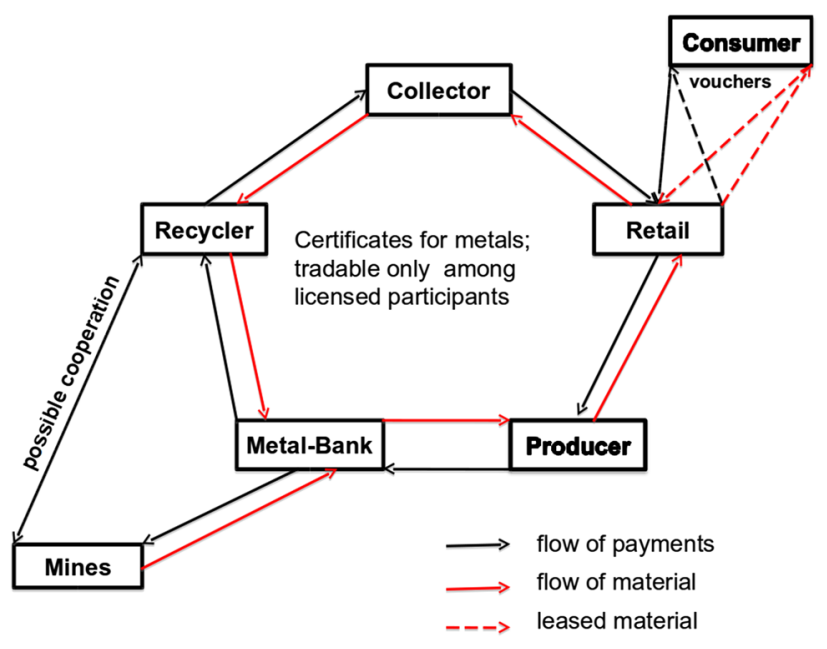

Fig. 4 The concept of metal bank 
definitely answered by a test in the real world. However, the existence and the popularity of future contracts in the financial world indicate that there is an interest in this kind of market management.

So, the metal bank would provide a service to industries and private consumers who both could find it attractive to deposit their monetary assets in a "real asset metal bank". Again, the concept is similar to that of the role played nowadays by banks which offer their vaults to customers to safely store precious metals and other valuables. Here, customers could be attracted to commodities which, unlike gold, have a value that goes beyond pure speculation, such as, for instance, platinum and the platinum group metals (Bardi and Caporali 2014).

The idea of the metal bank involves generating a closed circle among the market participants in order to reduce the influence of speculation. Over time, the bank can accumulate significant stocks of physical resources, usable to dampen extreme price fluctuations from the open market, caused by political or speculative influences. It is a similar model as the one that OPEC is said to practice for crude oil, as described earlier on. The assumption of a price dampening effect is justified by the cost advantage for fresh material in the circle. As there is no continuous trade, e.g. for rare-earth metals, on regular bourses, price building is made by daily fixings, similar to the procedure in the diamond market. Buyers of electronic equipment (in the chart designed as consumers) get vouchers for the metal content in the devices instead of certificates. This stimulates the closed-loop economy but avoids outside speculation and trade by parties, which are neither on the producing nor on the extraction side.

The metal bank is not just a short-term patch to mitigate the depletion problem. It is, rather, a step in the direction of a circular economy. Such an approach requires much more care in the handling of the material flow than it has ever been obtained so far. In practice, it requires a change in behaviour of consumers. The most effective motive that can lead consumers not to throw away material and to give value to it is their purse. Therefore, we have to redesign the function of a product, away from possession towards renting and leasing (see Fig. 5).

If consumers recognize a real and substantial value in some products, they may change their behaviour. There are already examples in the market of consumer behaviour that seemed to be entrenched and impossible to change, but that is seeing a true revolution nowadays. A good example is that of cars, where we are seeing a major shift from private ownership to lease. In this, as in other cases, (e.g. software) the consumers pay for the use of a product and its intangible value, not for ownership. In the case of a metal bank, customers would pay for the materials they obtain from the bank; however, these materials would be seen as "on

\section{Changing the Sales Concept for Consumer Electronics} Retailer Customer Producer

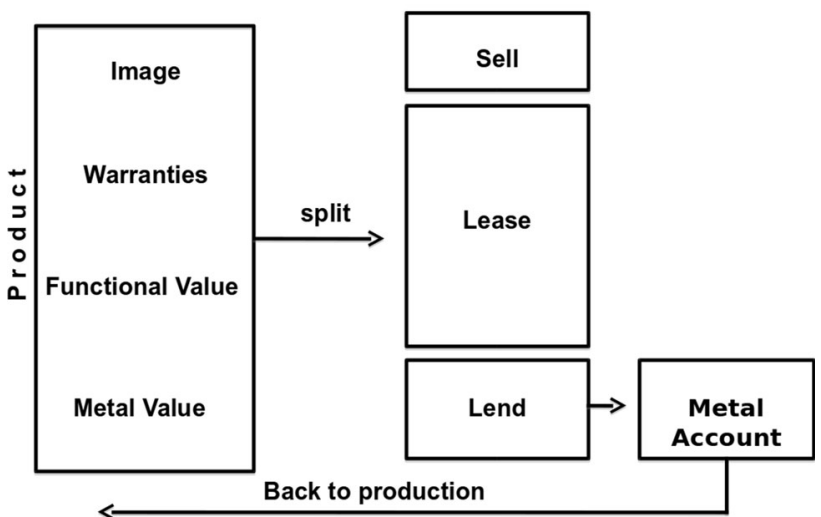

Fig. 5 Concepts associated to the metal bank

lease", and the customers would get a credit from their "metal bank account" when they bring the materials back to the bank, after the completion of the life cycle of the product. Actually, the bank would more likely buy the materials from refiners who would take care of recycling the discarded products, but that does not change the basic idea described here. Over a certain period of time, enough metals are aggregated to build up a sufficient stock, ensure supply and price stability. In this way, a metal bank would slowly free the industries out of the hands of speculators, who contribute nothing to the value chain.

The concept of a "metal bank" would be especially interesting for the case of minerals important to electronics and to the clean energy sector. An example is that of rareearth minerals, commonly used to manufacture computer components, wind turbines and electric vehicles. The stocks of easily extractable ores for these finite resources are rapidly diminishing and that is gradually forcing manufacturers to develop recycling methods. A few countries including Japan have already turned to taking apart items in waste steam such as old cell phones and old computers to recycle minerals within them. In the future, this may also happen to the hybrid vehicles where the electric motor and the battery contains few kilograms of rare-earth material such as neodymium (1 kg per vehicle) and lanthanum (10-15 kg per vehicle) (Stephenson 2013). For these metals, it seems that the classic demand and supply relation for price determination is not valid any more, since price increases of $1000 \%$ and more have been observed which defy rational explanation. This phenomenon may be at work in other sectors of the mineral commodity market. Speculation, rumours and probable disinformation distort traditional price-cost relations to an unacceptable extent.

Recently, a number of Japanese companies announced their plans to develop facilities for the recovery of rare-earth 
material business (Rare-Earth Separation Facilities-Innovation Metals Corp 2013). Hitachi announced the plans to use "mineral harvesting machinery" that can extract about 100 rare-earth magnets per hour from old hard disk drives. This automated process is about eight times faster than the manual labour-intensive practice. Shin-Etsu Chemical also announced plans to extract rare-earth metals from discarded air conditioners and recycle them in magnets. Tokyo-based chemical maker Showa Denko KK opened a plant in Vietnam to begin recycling metals such as dysprosium and didymium, which are used to make magnetic alloys and plans on having an output of $800 \mathrm{t}$ at the Vietnamese recycling factory. These facilities are still under development, but the tendency is clear. Given the strategic importance of rare-earth metals, it is possible that the concept of stockpiling them could become attractive in the future, developing some kind of "metal bank" concept that will go beyond the simple recycling of used electronic equipment.

\section{Conclusion}

Without reliable and continuous supply, especially with rare-earth metals and semi conductors, our high technology could face a total collapse. While in the future the problem will be solved only by means of a completely closed-cycle economy, in the near term the fluctuations and the shortages in the availability of metal commodities could be mitigated by stockpiling them. The proposed concept of a metal bank could manage these stockpiled resources and strengthen the development efforts of developing nations, which often serve only as suppliers of raw materials and do not upgrade their own industries in the value chain. Managing the metallic assets would also mean that the bank will have a dampening influence on irrational price fluctuations in the metal markets. Whether such a bank will be developed in the future remains to be seen, but the unavoidable, gradual depletion of high-grade ores makes such a concept worth investigating already at the present time.

Acknowledgments One of the authors (U.B.) acknowledges support from the Consorzio Interuniversitario per la Scienza e la Tecnologia dei Materiali (INSTM) for the preparation of the present paper.

\section{Compliance with Ethical Standards}

Conflict of interest The authors report no conflict of interest.

\section{References}

Ace (2008) Saudi Arabia's crude oil reserves propaganda. Oil Drum. http://www.theoildrum.com/node/3665. Accessed 3 July 2015
Areddy JT (2011) China moves to strengthen grip over supply of rareearth metals. http://www.wsj.com/articles/SB100014240527 48704124504576117511251161274

Ashby MF (2016) Materials and sustainable development, materials and sustainable development. Elsevier, Amsterdam. doi:10.1016/ B978-0-08-100176-9.00014-1

Bardi U (2014) The mineral question: how energy and technology will determine the future of mining. Energy Syst Policy, Front. doi:10.3389/fenrg.2013.00009

Bardi U, Caporali S (2014) Precious metals in automotive technology: an unsolvable depletion problem? Minerals 4:388-398. doi:10. $3390 / \min 4020388$

Barnett HJ, Morse C (1963) Scarcity and growth. Johns Hopkins University Press for the Future, Baltimore

Bianciardi C, Tiezzi E, Ulgiati S (1993) Complete recycling of matter in the frameworks of physics, biology and ecological economics. Ecol Econ 8(1):1-5. doi:10.1016/0921-8009(93)90026-3

Bradley RL (2007) Resourceship: an Austrian theory of mineral resources. Rev Austrian Econ 20:63-90. doi:10.1007/s11138006-0008-7

Brown TJ, Shaw RA, Bide T, Petavratzi T, Raycraft ER, Walters SA (2013) World mineral production 2007-2011. Keyworth, Nottingham

Buchert M, Manhart A, Bleher D, Pingel D (2012) "Recycling critical raw materials from waste electronic equipment" Report to the North RhineWestphalia State Agency for Nature, Environment and Consumer Protection. http://www.oeko.de/oekodoc/1375/ 2012-010-en.pdf. Accessed 23 Mar 2016

CIA (2014) The world factbook. https://www.cia.gov/library/publica tions/the-world-factbook/geos/us.html

Constantinescu C, Mattoo A, Ruta M (2015) The global trade slowdown: cyclical or structural? IMF working paper. https://www.imf.org/ external/pubs/ft/wp/2015/wp1506.pdf. Accessed 7 Mar 2016

Goeller H, Weinberg A (1978) Age of substitutability: what do we do when the mercury runs out. Am Econ Rev 68:1-11

Gutberlet J (2010) Waste, poverty and recycling. Waste Manag 30:171-173. doi:10.1016/j.wasman.2009.11.006

Heinberg R (2006) The oil depletion protocol. New Society Publishers, Trowbridge

Hotelling H (1931) The economics of exhaustible resources. J Polit Econ 39:137-175

Houthakker HS (2002) Are minerals exhaustible? Q Rev Econ Financ 42:417-421

Jacks DS (2013) From boom to bust: a typology of real commodity prices in the long run (No. 18874). doi:10.3386/w18874

Jogmec (n.d.) Rare Metals Stockpiling Program: Stockpilingl JOGMEC. http://www.jogmec.go.jp/english/stockpiling/stockpil ing_10_000001.html. Accessed 23 May 2016

Jakobi R (2011) Strategische Rohstoffe-Warten bis es dunkel wird? Nachr Chem 59:440-443

Jakobi R (2014) Rohstoffmärkte-Handel mit Kupfer und heisser Luft. Nachr Chem 62:51-52

Jevons WS (1866) The coal question, 2nd edn. Macmillan and Co, New York

Kamei T (2012) Recent research of thorium molten-salt reactor from a sustainability viewpoint. Sustainability 4:2399-2418. doi:10. 3390/su4102399

Krook J, Baas L, Jones PT, Geysen D, Tielemans Y, Van Passel S, Pontikes Y, Blanpain B, Quaghebeur M, Hoekstra N (2013) Enhanced landfill mining in view of multiple resource recovery: a critical review. J Clean Prod 55:45-55

Meadows DH, Meadows DL, Randers J, Bherens III W (1972) The limits to growth: a report to the club of Rome. New York, Universe Books

Meadows DH, Randers J, Meadows DL (2004) Limits to growth: the 30 year update. White River Junction, Chelsea Green 
Popescu G, Nica E (2014) The roots of china's economic slowdown. Knowl Horizons-Econ 6:14-17

Rare-Earth Separation Facilities-Innovation Metals Corp (2013) http://www.innovationmetals.com/rare-earth-separation-facilities/. Accessed 2 Jan 2015

Reynolds DB (1999) The mineral economy: how prices and costs can falsely signal decreasing scarcity. Ecol Econ 31:155-166

Simmons M (2005) Twilight in the desert: the coming Saudi oil shock and the world economy. Hoboken, New Jersey, John Wiley and Sons

Simon J (1981) The ultimate resource. Princeton University Press, Princeton

Simon J (1996) The ultimate resource 2. Princeton University Press, Princeton

Sprott E, Baker D (2012) Sprott Global Resource Investments Ltd. http://sprottglobal.com/markets-at-a-glance/maag-article/?id= 6590. Accessed 13 June 2015

Stephenson K (2013) Recyling rare earth minerals. http://www. greensolutionsmag.com/?p=1750
Strategic and Critical Materials: Report on stockpile requirements (2013) Report to the Office of the Under Secretary of Defense for Acquisition, Technology and Logistics. http://mineralsmake life.org/assets/images/content/resources/Strategic_and_Critical_ Materials_2013_Report_on_Stockpile_Requirements.pd. Accessed 23 May 2016

Sverdrup HU, Koca D, Rganarsdottir KV (2012) Peak metals, minerals, energy, wealth, food and population; urgent policy considerations for a sustainable society. J Environ Sci Eng B $1: 499-533$

Tremblay C, Gutberlet J, Peredo AM (2010) United we can: resource recovery, place and social enterprise. Resour Conserv Recycl 54:422-428. doi:10.1016/j.resconrec.2009.09.006

Turner G (2008) A comparison of the limits to growth with 30 years of reality. Glob Environ Chang 18:397-411. doi:10.1016/j. gloenvcha.2008.05.001

Valero A, Valero A (2014) Thanatia: the destiny of the earth's mineral resources. World Scientific Publishing Company, Singapore 